\title{
Estrutura e composição florística do estrato herbáceo- subarbustivo de um pasto abandonado na Reserva Biológica de Poço das Antas, município de Silva Jardim, RJ
}

\author{
Cláudia M. Vieira ${ }^{1}$ \\ Solange de V. A. Pessoa ${ }^{2}$
}

\begin{abstract}
RESUMO
A Reserva Biológica de Poço das Antas, situada no município de Silva Jardim, Rio de Janeiro apresenta cobertura vegetal formada por áreas de campos, capoeiras, capoeirões e fragmentos florestais. Este trabalho realizou o levantamento florístico e a análise da estrutura do componente herbáceo/subarbustivo de área de pasto abandonado, visando obter informações que auxiliem o estudo do processo de regeneração natural da área. A área de estudo apresenta indivíduos lenhosos, distribuídos esparsamente ou em moitas, tendo sido utilizada como pasto em tempos anteriores a criação da Reserva. O levantamento da vegetação foi efetuado através do método de pontos e revelou o predomínio de espécies de gramíneas e ervas ruderais, como Imperata brasiliensis, Lygodium volubile e Blechnum serrulatum.
\end{abstract}

Palavras chave: pasto abandonado, recuperação de áreas degradadas, método de pontos.

\begin{abstract}
The vegetation of the Poço das Antas Biological Reserve located in Silva Jardim municipality is composed of abandoned farmland and secondary forests fragments at different stages of development. A study of the floristic composition and structure of the shrub and herbaceous layer of an old field was conducted, aiming to obtain informations that might assist studies on natural regeneration of the site. The study area consists of an area that was once covered by forest and was used as pasture before the creation of the Biological Reserve. It is now covered by grassy vegetation with sparsely scattered woody plants or small thickets. The point method was used in the vegetation survey (total of 300 point). Grass species as Imperata brasiliensis, Lygodium volubile and weedy species as Blechnum serrulatum are dominant.
\end{abstract}

Keywords: old field, recovery of degraded areas, point method.

\section{INTRODUÇÃO}

A região das planícies aluviais e pequenos morros mamelonares da planície costeira do Estado do Rio de Janeiro, representa a área de domínio fisionômico da Floresta Ombrófila Densa das terras baixas (Velloso, Rangel Filho \& Lima, 1991), em alguns trechos sujeita a inundações periódicas ocasionadas pelas cheias dos rios e pequenos córregos que cortam a região. O fácil acesso e a proximidade aos primeiros centros urbanos do país impeliram a ocupação humana desta região, alterando a cobertura vegetal original, hoje restrita a pequenos remanescentes, e transformando a paisagem em extensas áreas de campos, capoeiras e capoeirões.

A cobertura vegetal da Reserva Biológica de Poço das Antas espelha a degradação ambiental atual das planícies costeiras do

\footnotetext{
${ }^{1}$ Bióloga. Instituto de Pesquisas Jardim Botânico do Rio de Janeiro, R. Pacheco Leão 915, 22460-030, Rio de Janeiro-RJ

${ }^{2}$ Pesquisadora Titular do Instituto de Pesquisas Jardim Botânico do Rio de Janeiro - Programa Mata Atlântica Rua Pacheco Leão, 915. CEP 22.460-030. RJ. email: spessoa@ jbrj.gov.br
} 
estado. A presença de áreas alteradas pela ação antrópica facilita a ação do fogo, constituindo uma ameaça à vida vegetal e animal existente, interrompendo e/ou dificultando o processo de regeneração natural da vegetação. Visando a obtenção de conhecimentos sobre o processo de regeneração natural, necessários à reabilitação da cobertura vegetal destas regiões na Reserva, uma série de estudos vêm sendo conduzidos em área de pasto abandonado com cerca de 20 anos de abandono.

No Brasil, nos últimos anos, alguns estudos (Matthes, 1992; Castellani, 1986; Sá, 1996; Buselato \& Bueno, 1981; Boldrini \& Eggers, 1996; Boldrini \& Miotto, 1987; Zocche \& Porto, 1993; Pessoa, Guedes-Bruni \& Kurtz, 1997; Araujo et al., 1997; Delamônica, 1997; Guedes, 1988; Mantovani, 1993; Tabarelli, Villani \& Mantovani, 1993, 1994; Buschbacher, Uhl \& Serrão, 1984; Guillaumon \& Fontes, 1992) têm enfocado a composição florística e a dinâmica de desenvolvimento de áreas degradadas, seja pela ação antrópica ou por fenômenos naturais. A variedade de respostas do meio ambiente frente à multiplicidade de formas e amplitude dos impactos e a crescente necessidade de expansão de novas fronteiras na utilização dos espaços naturais, apontam a urgência na realização de estudos com esta abordagem.

As interações das espécies com o meio e com outras espécies seriam os agentes controladores da invasão e do estabelecimento de espécies arbustivas e arbóreas (Myster, 1993), destacam-se, entre estas, a competição entre espécies herbáceas e sementes e plântulas de espécies arbustivas e arbóreas. Neste âmbito, pretende-se através do levantamento da composição florística e da estrutura do componente herbáceo/ subarbustivo, descrever a vegetação dos estágios iniciais de recomposição da cobertura vegetal e, de forma secundária, auxiliar iniciativas de restauração de áreas degradadas.

\section{MATERIAL E MÉTODOS}

A Reserva Biológica de Poço das Antas (22 $\left.30^{\prime}-22^{\circ} 33^{\prime} \mathrm{S}, 42^{\circ} 5^{\prime}-42^{\circ} 19^{\prime} \mathrm{W}\right)$ está situada no município de Silva Jardim, estado do Rio de Janeiro, com superfície de cerca de 5000 ha (IBDF/FBCN, 1981). Nos tempos anteriores à criação da Reserva, a região abrigava diversas fazendas de criação de gado, onde haviam algumas culturas de subsistência, pomares, pastos e remanescentes florestais. Com a criação da Reserva em 1974, a exploração destas terras teve fim em meados de 1976/1978. Deste modo, a cobertura vegetal da Reserva é atualmente constituída por áreas de formação pioneira com influência fluvial, campos antrópicos, capoeiras aluviais, capoeiras submontanas, florestas aluviais e florestas submontanas (Programa Mata Atlântica, 1996). Os fragmentos florestais remanescentes são testemunhos das matas que originalmente recobriam as planícies aluviais e morros mamelonares da planície costeira fluminense.

O clima da região é quente e úmido com estação chuvosa no verão, sem inverno pronunciado e as temperaturas médias anuais são elevadas durante quase todo o ano. A média das temperaturas máximas é de $30^{\circ} \mathrm{C}$ $32^{\circ} \mathrm{C}$ e as mínimas não ultrapassam os $18^{\circ} \mathrm{C}$. A precipitação média anual é de $1.000 \mathrm{~mm}$ e está concentrada nos meses de outubro a abril, sendo julho e agosto os meses menos chuvosos (IBDF/FBCN, 1981).

Os solos são bastante diversificados, em função do substrato geológico e das condições pedogenéticas locais, desta forma ocorrem Latossolo Vermelho Amarelo e Cambissolo nos morros mamelonares e Solos Gleizados, Orgânicos e Aluviais nas planícies de inundação e aluviais (Takizawa, 1995).

$\mathrm{O}$ trecho estudado corresponde a antiga área de mata de planície aluvial, aberta para estabelecimento de pastagem (figs. 1). $\mathrm{O}$ uso como pastagem tem cerca de 20 anos de abandono e, atualmente, a área apresenta vegetação predominantemente herbácea, com indivíduos lenhosos distribuídos esparsamente 


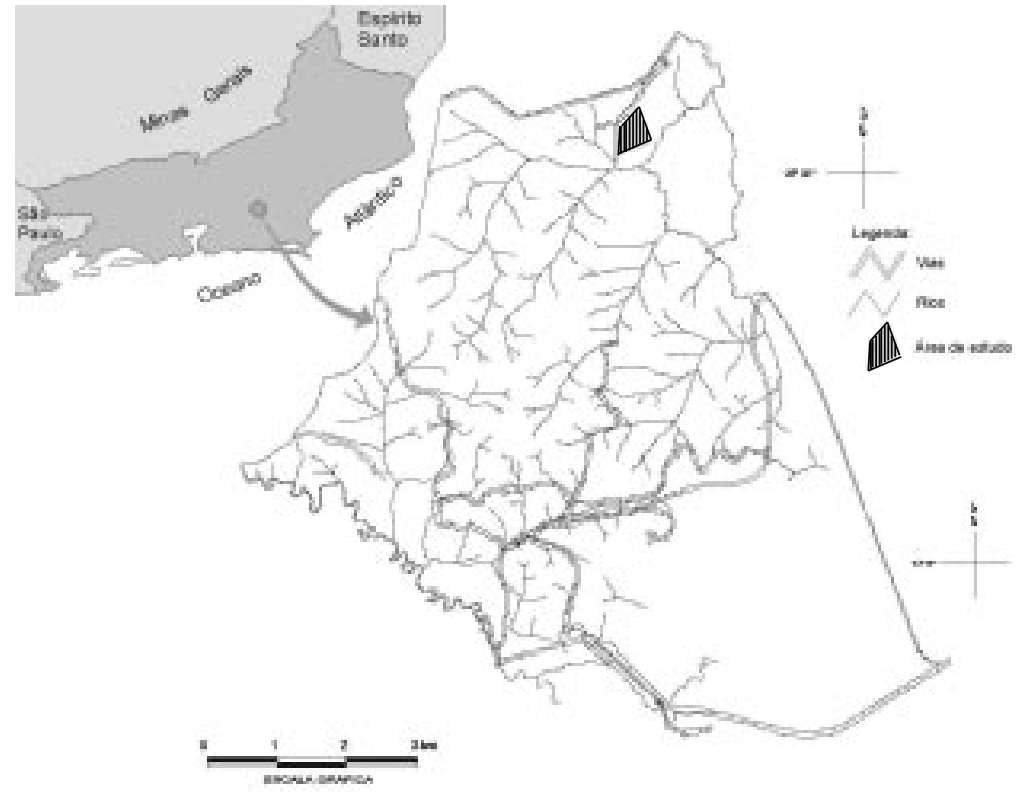

Figura 1 - Mapa da Reserva Biológica de Poço das Antas. Fonte: PMA/JBRJ

ou em moitas. Afastada cerca de $100 \mathrm{~m}$ da BR-101, apresenta ao norte pequena mancha de capoeira aluvial e na direção sul estreita faixa de mata ciliar. O solo no trecho estudado está representado pela associação de Solos Aluviais e Gleissolos (Takizawa, 1995), apresentando trechos com pequenas depressões que podem permanecer alagados durante alguns períodos do ano.

Para avaliação qualitativa e quantitativa dos elementos herbáceos/subarbustivos da vegetação, foi empregado o método de pontos com as modificações propostas por Mantovani (1987), associado a coletas aleatórias. O método de pontos vem sendo utilizado em investigações de formações herbáceas e pastagens, ou ainda na descrição dos estratos inferiores em comunidades mais estratificadas (Buselato \& Bueno, 1981; Mantovani, 1987; Fabris \& Pereira, 1990; Sá, 1996; Almeida \& Araújo, 1997). Como os demais métodos apresenta limitações e diversos fatores podem influir nos seus resultados (Mantovani \& Martins, 1990). Foram amostrados 300 pontos em 3 linhas de 100 m cada, com orientação SN. Em cada linha, a intervalos de $50 \mathrm{~cm}$, uma agulha, marcada com tintas coloridas a intervalos de $5 \mathrm{~cm}$ com cerca de $3 \mathrm{~mm}$ de diâmetro e $2 \mathrm{~m}$ de altura, foi solta verticalmente e, no ponto, anotadas as espécies tocadas pela agulha, o número de toques e a altura do toque na agulha. Todos os indivíduos tocados pela agulha, independentemente do seu hábito, foram amostrados. Pontos com solo desnudo também foram considerados, entendendo-se aqui solo desnudo como ponto sem ocorrência de toque.

Foram considerados os seguintes parâmetros fitossociológicos (Mantovani, 1987):

Média de toques: $\mathrm{MT}_{\mathrm{i}}=\mathrm{NT}_{\mathrm{i}} / \mathrm{NP}_{\mathrm{i}}$ Frequiência absoluta: $\mathrm{FA}_{i}=100 . \mathrm{NP}_{i} / \mathrm{NTP}$ Frequiência relativa: $\mathrm{FR}_{\mathrm{i}}=100 . \mathrm{NP}_{\mathrm{i}} / \sum \mathrm{NP}$ Cobertura: $\mathrm{CR}_{\mathrm{i}}=\left(100-\mathrm{N}_{\mathrm{O}}\right) \cdot \mathrm{FA}_{\mathrm{i}} / \sum \mathrm{FA}$

Vigor absoluto: $\mathrm{VA}_{\mathrm{i}}=100 . \mathrm{NT}_{\mathrm{i}} / \mathrm{NTP}$

Vigor relativo: $\mathrm{VR}_{\mathrm{i}}=100 . \mathrm{NT}_{\mathrm{i}} / \mathrm{NTT}$

Índice de cobertura: $C_{i}=F_{i}+V A_{i}$ Índice de valor de cobertura $: \mathrm{VC}=\mathrm{FR}_{\mathrm{i}}+\mathrm{VR}_{\mathrm{i}}$

$\mathrm{NT}_{\mathrm{i}}=$ No. toques da espécie $\mathrm{i}$

$\mathrm{NPi}=$ No. pontos com a espécie $\mathrm{i}$

NTP $=$ No. total de pontos

No $=$ Porcentagem de pontos sem toques

NTT $=$ No. total de toques 
Tabela 1 - Lista das espécies levantadas na área de vegetação campestre da Reserva Biológica de Poço das Antas pelo método de pontos $(*)$ e por coletas aleatórias $(+)$.

\begin{tabular}{|c|c|}
\hline CRIPTÓGAMAS & Leguminosae \\
\hline Blechnaceae & Andira anthelmia (Vell.) Macbr. + \\
\hline Blechnum serrulatum Rich. * & Aeschynomene sensitiva $\mathrm{Sw} . *$ \\
\hline Osmundaceae & Crotalaria pallida Ait. * \\
\hline Osmunda cinnamomea L. * & Dalbergia frutescens var. frutescens (Vell.) Britt. + \\
\hline Pteridaceae & Desmodium adscendens (Sw.) DC. * \\
\hline Adiantum serrato-dentatum Willd. * & Erythrina speciosa Andr. + \\
\hline Schizaeaceae & Inga edulis (Vell.) Mart. ex Benth. + \\
\hline Lygodium volubile $\mathrm{Sw} . *$ & Lonchocarpus cultratus (Vell.) Az.-Tozzi + \\
\hline Thelypteridaceae & Malvaceae \\
\hline \multirow[t]{2}{*}{ Thelypteris dentata (Forssk.) E. St. John * } & Urena lobata L. * \\
\hline & Melastomataceae \\
\hline FANERÓGAMAS & Clidemia biserrata DC. * \\
\hline Apocynaceae & Clidemia hirta (L.) Don. * \\
\hline Rauvolfia grandiflora Mart. ex DC. + & Miconia calvescens DC. + \\
\hline Bignoniaceae & Miconia prasina $($ Sw.) DC. + \\
\hline Arrabidea selloi (Spreng.) Sandw. + & Miconia serrulata DC. + \\
\hline Boraginaceae & Miconia staminea DC. * \\
\hline Cordia corymbosa (L.) Don. * & Tibouchina gracilis (Bonpl.) Cogn. + \\
\hline Commelinaceae & Meliaceae \\
\hline Commelina $\operatorname{sp~} 1 *$ & Guarea guidonea (L.) Sleumer* \\
\hline Compositae & Guarea macrophyla Vahl. + \\
\hline Baccharis dracunculifolia DC. + & Moraceae \\
\hline Baccharis trimera (Less.) DC. + & Cecropia lyratiloba Miq. + \\
\hline Eupatorium vitalbae DC. * & Myrsinaceae \\
\hline Vernonia $\mathrm{sp} *$ & Rapanea ferruginea (R. et P.) Mez. * \\
\hline Cucurbitaceae & Myrtaceae \\
\hline Melothria fluminensis Gardn. + & Psidium guayava Raddi * \\
\hline Cyperaceae & Psidium guineensis $\mathrm{Sw} .+$ \\
\hline Cyperus sp * & Piperaceae \\
\hline Scleria sp * & Piper mollicomum Kunth. * \\
\hline Euphorbiaceae & Polygonaceae \\
\hline Alchornea triplinervia Muell. Arg. + & Polygonum acuminatum H.B.K. + \\
\hline Flacourtiaceae & Rubiaceae \\
\hline Casearia sylvestris Swartz. + & Psychotria $\mathrm{sp}+$ \\
\hline Gramineae & Randia armata DC. + \\
\hline Andropogon bicornis L. + & Sabicea aspera var. glabrescens (Benth.) Schum. * \\
\hline Andropogon sp $1+$ & Smilacaceae \\
\hline Andropogon sp $2+$ & Smilax elastica Griseb. + \\
\hline Digitaria insularis (L.) $\mathrm{Mez}+$ & Smilax quinquenervia Vell. + \\
\hline Eleusine indica (L.) Gaertn. * & Tiliaceae \\
\hline Hyparhenia rufa (Nees) Stapf $*$ & Luehea grandiflora Mart. ex Zucc. + \\
\hline Imperata brasiliensis Trin. * & Verbenaceae \\
\hline Melinis minutiflora Beauv. * & Lantana camara L. * \\
\hline Panicum maximum Jacq. * & Vitex polygama Cham. + \\
\hline Panicum rivulare Trin. * & Vitaceae \\
\hline Panicum pilosum $S w . *$ & Cissus erosa L.C.Rich. * \\
\hline Paspalum millegrana Schrad. * & Zingiberaceae \\
\hline Saccharum $\mathrm{sp}+$ & Hedychium coronarium Koenig. * \\
\hline Labiatae & Indeterminada \\
\hline Hyptis brevipes Poit. * & Indet $\mathrm{sp} *$ \\
\hline
\end{tabular}


O levantamento florístico foi efetuado de junho de 1993 a junho de 1994 e a coleta de dados fitossociológicos realizada em junho de 1994. O material coletado foi identificado utilizando-se bibliografia especializada, consulta a especialistas e material de herbário, estando as exsicatas dos materiais depositadas no herbário do Jardim Botânico do Rio de Janeiro.

\section{RESULTADOS E DISCUSSÃO}

Os 300 pontos amostraram 37 espécies distribuídas em 24 famílias, 33 gêneros, sendo 19 famílias de fanerógamas e 5 de criptógamas. Coletas aleatórias acresceram à lista 31 espécies (tabela 1). A análise das espécies quanto ao hábito, revelou o predomínio de herbáceas (46\%) sobre as arbóreas $(23 \%)$, arbustivas (21\%) e trepadeiras $(10 \%)$.

$\mathrm{O}$ resultado obtido no que tange ao número de espécies por família, apresentou pequena variação, sendo a família Gramineae a de maior número de espécies (8), seguida de Melastomataceae e Leguminosae, com 3 espécies e de Compositae e Cyperaceae, com 2 espécies cada, as demais se fizeram representar por somente uma espécie.

Vieira, Uhl \& Nepstad (1994), Uhl, Buschbacher \& Serrão (1988) e Buschbacher, Uhl \& Serrão (1984), estudando áreas de pastos abandonados na região da Amazônia Central, assinalaram existir uma grande diferença na riqueza total e na composição de espécies conforme a intensidade de uso da área, isto é, uso leve e uso intenso. Observaram que quanto maior a perturbação menor a riqueza e maior o predomínio de espécies pioneiras, e que as perturbações provocadas pelo uso da área como pastagem geram efeitos maiores e mais prolongados do que a agricultura de subsistência, no processo sucessional.
Para uma floresta de restinga recém derrubada sobre solo arenoso, Sá (1996) aponta Gramineae e Compositae entre as famílias de maior abundância de espécies, embora diferentemente deste estudo, o hábito trepador tenha apresentado um predomínio sobre os demais hábitos observados. Buselato \& Bueno (1981), utilizando o método de pontos e trabalhando em campos com história diferenciada de uso como pastagem, encontraram as Gramineae, Compositae e Cyperaceae como as famílias mais abundantes e as demais 16 famílias com três, duas ou uma espécie. O campo onde a atividade pastoril cessou, apresentou um acréscimo de seis espécies de gramíneas, porém, no geral, o campo pastejado apresentou maior riqueza de espécies e famílias, possivelmente ocasionado pela constante perturbação provocada pelo pastoreio, que embora favoreça o aparecimento de áreas de solo desnudo atua como agente "facilitador" no estabelecimento de outras espécies (Pandey \& Singh, 1991, apud Boldrini \& Eggers, 1996). Modificações na composição florística da vegetação, com substituição de formas de crescimento dominantes e evidência de espécies beneficiadas pela exclusão ou pelo pastoreio são apontadas em Boldrini \& Eggers (1996).

Os parâmetros fitossociológicos obtidos são apresentados, em ordem decrescente de VC, na tabela 2 .

Dos 300 pontos amostrados, 45,33\% apresentaram uma espécie por ponto, sendo 4 o valor máximo de espécies encontrado em um único ponto. $\mathrm{O}$ valor de $3,17 \%$ obtido para a porcentagem de solo descoberto indica uma cobertura homogênea do solo.

Uma estreita correlação entre a presença de Imperata brasiliensis e baixo percentual de solo desnudo é demonstrado por Guillaumon \& Fontes (1992), que associam 
Tabela 2 - Relação das espécies amostradas e seus parâmentros fitossociológicos para área de vegetação campestre da Reserva Biológica de Poço das Antas: NT - no. de toques, NP - no. de pontos, MT - média de toques, FA - freqüência absoluta, FR - frequiência relativa (\%), CR - cobertura relativa (\%), VA - vigor absoluto (\%), VR - vigor relativo (\%),

$\mathrm{C}$ - índice de cobertura (\%), VC - índice de valor de cobertura (\%)

\begin{tabular}{|c|c|c|c|c|c|c|c|c|c|c|}
\hline ESPÉCIE & NT & NP & MT & FA & $\mathbf{F R}$ & CR & VA & VR & C & VC \\
\hline Imperata brasiliensis & 346,00 & 188,00 & 1,84 & 62,67 & 40,78 & 60,68 & 115,33 & 43,85 & 178,00 & 84,63 \\
\hline Lygodium volubile & 82,00 & 53,00 & 1,55 & 17,67 & 11,50 & 17,11 & 27,33 & 10,39 & 45,00 & 21,89 \\
\hline Blechnum serrulatum & 47,00 & 33,00 & 1,42 & 11,00 & 7,16 & 10,65 & 15,67 & 5,96 & 26,67 & 13,12 \\
\hline Sabicea aspera var. glabrescente & 45,00 & 28,00 & 1,61 & 9,33 & 6,07 & 9,04 & 15,00 & 5,70 & 24,33 & 11,78 \\
\hline Hedychium coronarium & 28,00 & 17,00 & 1,65 & 5,67 & 3,69 & 5,49 & 9,33 & 3,55 & 15,00 & 7,24 \\
\hline Hyparrhenia rufa & 31,00 & 15,00 & 2,07 & 5,00 & 3,25 & 4,84 & 10,33 & 3,93 & 15,33 & 7,18 \\
\hline Panicum maximum & 21,00 & 15,00 & 1,40 & 5,00 & 3,25 & 4,84 & 7,00 & 2,66 & 12,00 & 5,92 \\
\hline Scleria sp. & 19,00 & 16,00 & 1,19 & 5,33 & 3,47 & 5,16 & 6,33 & 2,41 & 11,67 & 5,88 \\
\hline Miconia staminea & 27,00 & 10,00 & 2,70 & 3,33 & 2,17 & 3,23 & 9,00 & 3,42 & 12,33 & 5,59 \\
\hline Thelypteris dentata & 20,00 & 12,00 & 1,67 & 4,00 & 2,60 & 3,87 & 6,67 & 2,53 & 10,67 & 5,14 \\
\hline Clidemia biserrata & 17,00 & 8,00 & 2,13 & 2,67 & 1,74 & 2,58 & 5,67 & 2,15 & 8,33 & 3,89 \\
\hline Vernonia sp & 19,00 & 6,00 & 3,17 & 2,00 & 1,30 & 1,94 & 6,33 & 2,41 & 8,33 & 3,71 \\
\hline Eupatorium vitalbae & 12,00 & 9,00 & 1,33 & 3,00 & 1,95 & 2,90 & 4,00 & 1,52 & 7,00 & 3,47 \\
\hline Paspalum millegrana & 11,00 & 8,00 & 1,38 & 2,67 & 1,74 & 2,58 & 3,67 & 1,39 & 6,33 & 3,13 \\
\hline Piper mollicomum & 10,00 & 6,00 & 1,67 & 2,00 & 1,30 & 1,94 & 3,33 & 1,27 & 5,33 & 2,57 \\
\hline Urena lobata & 10,00 & 3,00 & 3,33 & 1,00 & 0,65 & 0,97 & 3,33 & 1,27 & 4,33 & 1,92 \\
\hline Rapanea ferruginea & 7,00 & 4,00 & 1,75 & 1,33 & 0,87 & 1,29 & 2,33 & 0,89 & 3,67 & 1,75 \\
\hline Clidemia hirta & 6,00 & 4,00 & 1,50 & 1,33 & 0,87 & 1,29 & 2,00 & 0,76 & 3,33 & 1,63 \\
\hline Psidium guayava & 5,00 & 3,00 & 1,67 & 1,00 & 0,65 & 0,97 & 1,67 & 0,63 & 2,67 & 1,28 \\
\hline Panicum rivulare & 3,00 & 3,00 & 1,00 & 1,00 & 0,65 & 0,97 & 1,00 & 0,38 & 2,00 & 1,03 \\
\hline Adiantum serrato-dentatum & 4,00 & 2,00 & 2,00 & 0,67 & 0,43 & 0,65 & 1,33 & 0,51 & 2,00 & 0,94 \\
\hline Cissus erosa & 2,00 & 2,00 & 1,00 & 0,67 & 0,43 & 0,65 & 0,67 & 0,25 & 1,33 & 0,69 \\
\hline Commelina sp. & 2,00 & 2,00 & 1,00 & 0,67 & 0,43 & 0,65 & 0,67 & 0,25 & 1,33 & 0,69 \\
\hline Desmodium adscendens & 2,00 & 1,00 & 2,00 & 0,33 & 0,22 & 0,32 & 0,67 & 0,25 & 1,00 & 0,47 \\
\hline Cecropia lyratiloba & 1,00 & 1,00 & 1,00 & 0,33 & 0,22 & 0,32 & 0,33 & 0,13 & 0,67 & 0,34 \\
\hline Cordia corymbosa & 1,00 & 1,00 & 1,00 & 0,33 & 0,22 & 0,32 & 0,33 & 0,13 & 0,67 & 0,34 \\
\hline Crotalaria pallida & 1,00 & 1,00 & 1,00 & 0,33 & 0,22 & 0,32 & 0,33 & 0,13 & 0,67 & 0,34 \\
\hline Eleusine indica & 1,00 & 1,00 & 1,00 & 0,33 & 0,22 & 0,32 & 0,33 & 0,13 & 0,67 & 0,34 \\
\hline Guarea guidonea & 1,00 & 1,00 & 1,00 & 0,33 & 0,22 & 0,32 & 0,33 & 0,13 & 0,67 & 0,34 \\
\hline Hyptis brevipes & 1,00 & 1,00 & 1,00 & 0,33 & 0,22 & 0,32 & 0,33 & 0,13 & 0,67 & 0,34 \\
\hline Indet. & 1,00 & 1,00 & 1,00 & 0,33 & 0,22 & 0,32 & 0,33 & 0,13 & 0,67 & 0,34 \\
\hline Lantana camara & 1,00 & 1,00 & 1,00 & 0,33 & 0,22 & 0,32 & 0,33 & 0,13 & 0,67 & 0,34 \\
\hline Aeschynomene sensitiva & 1,00 & 1,00 & 1,00 & 0,33 & 0,22 & 0,32 & 0,33 & 0,13 & 0,67 & 0,34 \\
\hline Mellinus minutiflora & 1,00 & 1,00 & 1,00 & 0,33 & 0,22 & 0,32 & 0,33 & 0,13 & 0,67 & 0,34 \\
\hline Osmunda cinnamomea & 1,00 & 1,00 & 1,00 & 0,33 & 0,22 & 0,32 & 0,33 & 0,13 & 0,67 & 0,34 \\
\hline Panicumpilosum & 1,00 & 1,00 & 1,00 & 0,33 & 0,22 & 0,32 & 0,33 & 0,13 & 0,67 & 0,34 \\
\hline \multirow[t]{2}{*}{ Cyperus sp } & 1,00 & 1,00 & 1,00 & 0,33 & 0,22 & 0,32 & 0,33 & 0,13 & 0,67 & 0,34 \\
\hline & 789,00 & 461,00 & 55,00 & 153,67 & 100,00 & 148,80 & 263,00 & 100,00 & 416,67 & 200,00 \\
\hline
\end{tabular}

o fato ao baixo nível de palatabilidade desta gramínea. Estes autores também assinalam ser esta espécie, bem como espécies de melastomatáceas, indicadoras de alto grau de deterioração do solo. Neste sentido, apesar de não terem sido efetuadas análises químicas, a alta incidência observada de Imperata brasiliensis, estaria apontando a presença de solos empobrecidos em grande proporção da área estudada, tendo em vista que outras espécies como Hyparrhenia rufa e Panicum maximum, estão presentes porém ocorrendo em menor frequiência, estão relacionadas a solos férteis (Leitão Filho, Aranha \& Bacchi, 1972; Nepstad, Uhl \& Serrão, 1991). A baixa disponibilidade de 
nutrientes no solo conduz à persistência de espécies de pouca demanda nutricional, restringindo o estabelecimento e crescimento de indivíduos arbustivos e arbóreos, normalmente dependentes de maior fertilidade.

Como já referido, Imperata brasiliensis foi a espécie que apresentou o maior valor de freqüência, vindo a seguir Lygodium volubile, Blechnum serrulatum e Sabicea aspera var. glabra, perfazendo em conjunto $65,51 \%$ do valor total da frequiência relativa. Um expressivo número de espécies $(37,8 \%)$ ocorreu em um único ponto, sendo estas consideradas raras na amostragem. Sá (1996) na restinga e Mantovani (1987) no cerrado, também registraram um número significativo de espécies ocorrendo em um único ponto.

As espécies Urena lobata $(3,3)$, Vernonia sp $(3,2)$ e Miconia staminea $(2,7)$ apresentaram as maiores médias de toques, embora ocorrendo em poucos pontos, possivelmente por se apresentarem ramificadas. Mantovani (1987) cita a forma de vida, o tamanho do indivíduo e a densidade dos agrupamentos como características que influenciam nos valores obtidos para os números de ocorrência e de toques.

A dominância de Imperata brasiliensis na vegetação é demonstrada pelo alto valor de vigor relativo $(43,85 \%)$ alcançado. No método de pontos, o valor de dominânciaé medido, de forma indireta, pela "percentage each species is contributing to the pasture sward" (Levy \& Madden, 1933, apud Mantovani \& Martins, 1990) e a "percentage of sward" (Goodall, 1952, apud Mantovani \& Martins, 1990), correspondendo ao vigor relativo (Mantovani \& Martins, 1990).

As espécies que apresentaram os maiores valores de vigor absoluto e relativo foram Imperata brasiliensis e Lygodium volubile. Estes parâmetros, segundo Mantovani \& Martins (1990), espelham a estratificação, sofrendo influência da forma de vida e do desenvolvimento das espécies, desta forma pode ser atribuído ao hábito em touceira o alto valor apresentado porImperata brasiliensis. Os resultados obtidos por Sá (1996) para Paspalum maritimum e para Rhynchelytrum repens, reafirmam a influência deste hábito de crescimento na obtenção de altos valores para estes parâmetros.

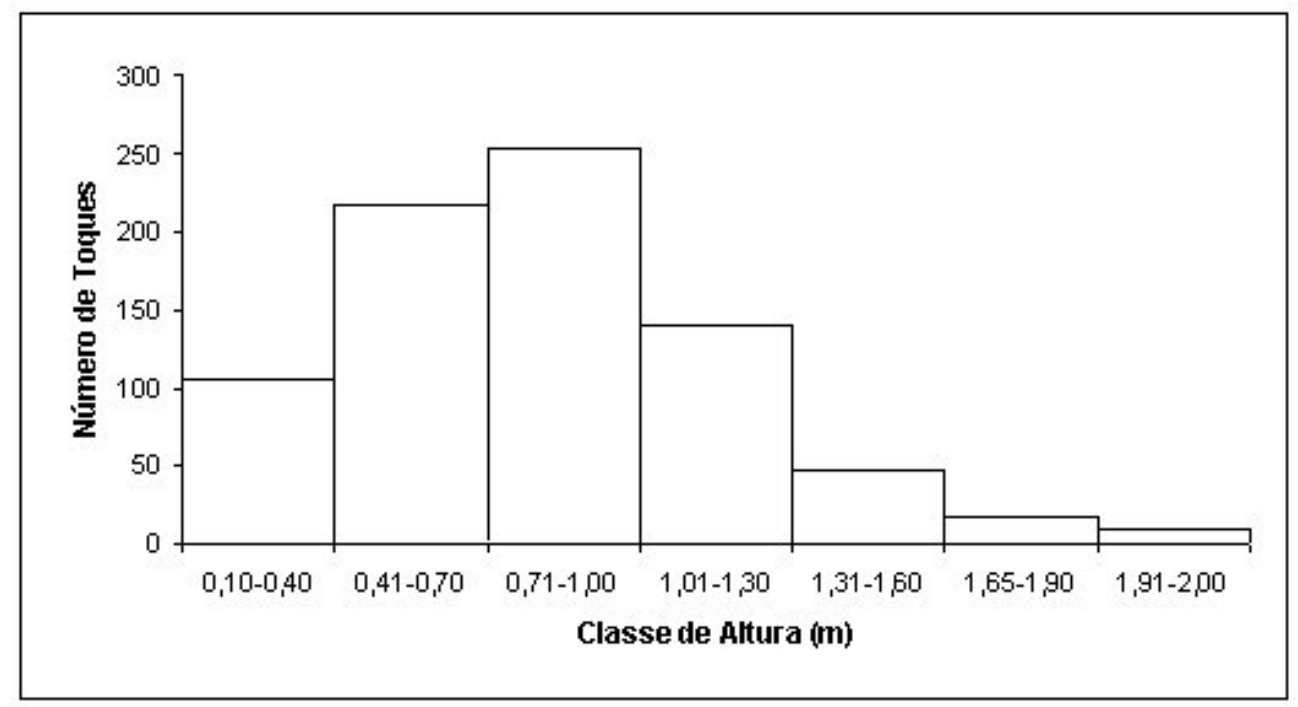

Figura 2 - Relação entre número de toques amostrados e classes de altura 
Os totais obtidos para vigor relativo e vigor absoluto (tabela 2 ) resultando no valor dos vigores absolutos maior que $100 \%$, indicam ser a vegetação bastante estratificada (Mantovani \& Martins,1990).

A estratificação também pode ser observada através da relação entre a altura e o número de toques obtidos (figura 2). Verifica-se maior concentração de toques na classe de altura entre $41 \mathrm{~cm}$ e $100 \mathrm{~cm}$, ocasionada pela abundância, forma de crescimento e morfologia foliar deImperata brasiliensis. O menor número de toques nas classes inferiores de altura pode ser devido ao vigoroso crescimento das partes aéreas desta espécie, o que resulta na deposição de grossa camada de folhas mortas, reduzindo a luminosidade próxima ao solo. Este fator, associado ao provável efeito alelopático atribuído àImperata brasiliensis (Kissmann \& Groth, 1997), seria de relevante importância no estabelecimento e no desenvolvimento de outras plantas nos locais dominados pela espécie.

A fisionomia campestre predomina na comunidade, porém a presença de moitas de diversos tamanhos com distribuição bastante espaçada, é notável visualmente. Embora espécies subarbustivas e arbustivas, a exemplo de Clidemia biserrata, Clidemia hirta, Lantana camara e Miconia staminea, constituam pequenos agrupamentos de uma ou várias espécies, são principalmente elementos lenhosos os principais formadores das moitas. O método utilizado não levantou estes dados, podendo o fato ser atribuído à distribuição espacial dos agrupamentos e a morfologia das espécies. Deve ser salientado que no processo de recobrimento de pastagens, indivíduos de subarbustos e árvores que conseguem ultrapassar a camada das gramíneas, promovem ações que irão facilitar o estabelecimento de elementos florestais, como aumento na dispersão e chuva de sementes, ao proporcionarem pontos de atração e/ou descanso para a fauna dispersora de sementes e sombreamento das gramíneas, com conseqüente diminuição da presença de roedores predadores de sementes e plântulas (Holl, 1999; Nepstad, Uhl \& Serrão, 1991).

O agrupamento de espécies em áreas abertas pode dar origem a formação de moitas, que com o seu crescimento em tamanho estabelecem condições microclimáticas que inibem odesenvolvimento de espécies heliófitas, favorecendo o estabelecimento de espécies arbustivas e arbóreas, ao proporcionarem melhores condições de umidade e luminosidade, dois dos principais recursos pelos quais as espécies vegetais competem em áreas de campos abandonados (Myster, 1993). A importância das moitas no processo de evolução da comunidade vem sendo enfatizada em estudos conduzidos em vegetação de restinga (Andrade, 1991; Montezuma, 1997; Zaluar, 1997).

Odum (1972) menciona que certas espécies tendem a possuir distribuição agregada, seja devido ao processo reprodutivo, seja em resposta a diferentes condições do habitat. Embora o método utilizado não tenha fornecido dados a este respeito, observou-se que em locais onde o solo apresenta maior umidade, podendo estar alagado em alguns períodos durante o ano, Hedychium coronarium forma agrupamentos densos, podendo provocar a exclusão de outras espécies, por sua agressividade e difícil erradicação (Kissmann \& Groth, 1997). Investigação conduzida na Reserva, em trecho de mata sujeita a inundações periódicas, indica serem estes locais preferenciais para a ocorrência de algumas espécies lenhosas, a exemplo de 
Estrutura e composição florística do estrato herbáceo-subarbustivo de um pasto abandonado na Reserva Biológica de Poço das Antas, município de Silva Jardim, RJ

Tabebuia cassinoides e Calophylum brasiliensis. Andropogon bicornis, Imperata brasiliensis, Hyparrhenia rufa e Panicum maximum por outro lado, apresentam preferência por áreas mais secas e outras espécies, como Polygonum acuminatum e Aeschynomene sensitiva, foram típicas de áreas mais úmidas. Referências sobre especificidade de espécies às condições de umidade do ambiente são encontradas nos estudos de Buselato \& Bueno (1981) e Zocche \& Porto (1993).

Das sete espécies mais importantes indicadas pela análise dos parâmetros fitossociológicos, cinco apresentam propagação vegetativa. Esta estratégia de regeneração, que concede a espécie vantagens na ocupação do espaço, está normalmente associada a espécies invasoras, a exemplo de Imperata brasiliensis, Hyparrhenia rufa e Hedychium coronarium. Estudos efetuados com plantas invasoras de culturas (Leitão Filho, Aranha \& Bacchi, 1972, 1975; Bacchi, Leitão Filho \& Aranha, 1984; Kissmann \& Groth, 1997) indicam ser este mecanismo utilizado, além das espécies acima citadas, por Panicum maximum, Desmodium adscendens, Andropogon bicornis e Lantana camara, também presentes na área. Grime (1979, apud Castellani, 1986) propõe que a reprodução vegetativa confere maior probabilidade de sobrevivência dos descendentes e rápida proliferação das espécies, quando em condições favoráveis.

Esta análise também assinalou um predomínio de gramíneas e ervas ruderais, de ampla distribuição geográfica (Leitão Filho, Aranha \& Bacchi ,1972, 1975; Bacchi, Leitão Filho \& Aranha,1984; Laca-Buendia, Brandão \& Gavillanes, 1989; Gavillanes \& D’Angieri Filho, 1991; Muenscher,1955) como Imperata brasiliensis, Panicum maximum, Hyparrhenia rufa, Lygodium volubile, Urena lobata, Osmunda cinnamomea, Eleusine indica e Blechnum serrulatum. Baker (1974, apud Castellani, 1986) e Good (1974, apud Castellani, 1986) associam o estabelecimento de espécies de ampla distribuição geográfica a áreas sujeitas a freqüentes ações perturbatórias. Purata (1986), estudando a florística e a estrutura de campos abandonados, observou que o favorecimento em direção a ocorrência predominante de espécies ruderais tende a retardar o processo sucessional, dificultando o estabelecimento de árvores de espécies pioneiras.

O predomínio de gramíneas e ervas perenes, provenientes da interferência antrópica sobre a paisagem da área estudada, remete a características próprias deste grupo, que têm implicações diretas sobre a trajetória sucessional da comunidade. A rápida taxa de crescimento e a morfologia e disposição foliar das gramíneas, além da deposição de grossa camada de folhas mortas, reduzem a disponibilidade de luz ao nível do solo, o que dificulta o estabelecimento e desenvolvimento de sementes e plântulas de elementos lenhosos. O sistema radicular superficial, peculiar a este grupo, aumenta a competição por nutrientes e água do solo, novamente interferindo no estabelecimento e crescimento de plântulas de indivíduos lenhosos. Agregado a estas características, Nepstad, Uhl \& Serrão (1991) citam a baixa disponibilidade de propágulos e a predação de sementes e plântulas de espécies arbóreas, bem como a competição de raízes entre estas e a vegetação de pastagens abandonadas, como barreiras ecológicas à regeneração florestal de pastagens abandonadas.

A localização da área estudada, situada próxima às margens da rodovia BR-101, associada a cobertura vegetal predominante, 
neste caso composta, em grande proporção, por gramíneas e ervas perenes, também favorece a ocorrência de incêndios. Logo após a realização do estudo, a área sofreu danos consideráveis provocados por fogo que se originou nas margens da rodovia. As gramíneas possuem alta flamabilidade, aumentando a probabilidade de queimadas devido ao acúmulo, acima do solo, de grossa camada de biomassa morta e a alta razão superfície/volume das folhas (Nepstad, Uhl \& Serrão, 1991, Mack \& D’Antonio,1998). A formação de uma cobertura homogênea facilita o alastramento e o aumento na intensidade do fogo, pois permite a livre circulação do vento, diferentemente de áreas florestadas, onde os elementos arbóreos funcionariam como obstáculos.

Outra característica que deve ser considerada é a grande resistência à ação do fogo apresentada pelas gramíneas e ervas perenes (Glenn-Lewin, Peet \& Veblen, 1992). A área estudada, após decorrido pouco tempo da queimada, apresentava intensa regeneração de gramíneas, em especial de Imperata brasiliensis, concordando com a afirmativa acima, acerca da resistência das gramíneas ao fogo e consequiente aumento do domínio destas, após queimadas. A frequiência na ocorrência de incêndios e o histórico e intensidade de uso da terra são fatores importantes quando se analisa o tempo necessário para que se proceda a reocupação do espaço com elementos arbustivos e/ou arbóreos. Não foram obtidos registros e/ou informações sobre a freqüência e a intensidade de incêndios na área de estudo, o que muito contribuiria na avaliação do papel do componente herbáceo e dos incêndios sobre a trajetória sucessional da comunidade em estudo. $\mathrm{O}$ retrocesso causado, ao processo sucessional por incêndios, provocando a morte de plântulas e indivíduos jovens, alterações no habitat disponível para a fauna e favorecimento de espécies que rebrotam após o fogo, como gramíneas, lianas e certas espécies de árvores, é mencionado por Nepstad, Uhl \& Serrão (1991) ao estudarem paisagens amazônicas degradadas.

Uhlet al. (1982) e Brinkmann \& Vieira (1971) salientam o papel danoso das altas temperaturas decorrentes de incêndios sobre o banco de sementes de espécies arbóreas, em áreas de floresta tropical. Brinkmann \& Vieira (1971) assinalam a quase total exclusão do banco de sementes pela ação de queimadas, ficando a regeneração amplamente dependente da chegada de novas sementes, pois os maiores danos ocorrem a profundidades onde estão localizadas a maioria das sementes, qual sejam, profundidades menores que $10 \mathrm{~cm}$. Ainda segundo estes autores, os efeitos de queimadas sobre sementes enterradas a profundidades maiores que $10 \mathrm{~cm}$ seriam dependentes da espécie, sendo algumas mais atingidas do que outras. $\mathrm{O}$ processo de regeneração de espécies arbóreas (Uhl et al., 1982) também pode ser significativamente influenciado pela ação de remoção das camadas do solo que contêm os estoques de sementes, plântulas e tecidos vegetativos, fato normalmente observado no uso de maquinaria pesada em práticas agrícolas.

Estudo conduzido por Garwood (1989, apudZahawi \& Augspurger, 1999) assinala que em pastagens, existe uma tendência ao predomínio, no banco de sementes, de sementes de gramíneas e ervas, com poucas de árvores. Embora não tenha sido efetuado estudo do banco de sementes, acredita-se que resultado semelhante possa ser obtido, demonstrando, então, a baixa contribuição do banco de sementes, para a regeneração desta área. 
Estrutura e composição florística do estrato herbáceo-subarbustivo de um pasto abandonado na

Embora existam fragmentos florestais vizinhos à área de estudo, que representam fonte potencial de propágulos, os resultados obtidos demonstram e nos levam a concluir que o componente herbáceo na área formando vegetação densa, vem exercendo forte domínio na manutenção da composição florística do trecho analisado ao dificultar o estabelecimento de espécies arbóreas e arbustivas pioneiras. Esta tendência é atenuada nos locais onde espécies arbustivas/ subarbustivas se agrupam, formando moitas. A possibilidade de ocorrência de incêndios também surge como forte indicador de permanência da atual comunidade durante longo período, devido em grande parte, à destruição das moitas, à redução do banco de sementes de espécies arbóreas e à manutenção de condições desfavoráveis à invasão e ao estabelecimento de espécies arbustivas e arbóreas.

\section{AGRADECIMENTOS}

Os autores agradecem a direção e equipe da Reserva Biológica de Poço das Antas pelo apoio e utilização da infra-estrutura da Reserva, aos colegas do Instituto de Pesquisas Jardim Botânico do Rio de Janeiro pelo auxílio na identificação do material botânico, ao botânico Luís Sérgio P. Sarahyba pela identificação das gramíneas, a Cyl Farney C. de Sá e Rejan R. Guedes-Bruni pelas valiosas críticas e sugestões ao artigo, a Dorothy S. D. de Araújo pelos importantes comentários aos diversos manuscritos deste artigo e à versão do abstratc e a Shell Brasil S/A e The John D. and Catherine T. MacArthur Foundation pelo suporte financeiro ao Programa Mata Atlântica. A autora Claudia M. Vieira agradece ao Programa Mata Atlântica/Fundação Botânica Margaret Mee pela bolsa concedida.

\section{REFERÊNCIAS BIBLIOGRÁFICAS}

Almeida, A. L. \& Araújo, D. S. D. 1997. Comunidades vegetais do cordão arenoso externo da Reserva Ecológica Estadual de Jacarepiá, Saquarema, RJ. In.Absalão, R.S. \& Esteves, A.M. (ed.) Ecologia de Praias Arenosas do Litoral Brasileiro. Oecologia Brasiliensis 3: 47-63.

Andrade, L. R. 1991. Análise estrutural e composição específica das comunidades vegetais de moitas de restinga, em Maricá - RJ. Universidade de Brasília, 94p. Dissertação de Mestrado. Departamento de Ecologia.

Araújo, D. S. D. de; Oliveira, R. R. de, Lima, E. \& Ravelli Neto, A. 1997. Estrutura da vegetação e condições edáficas numa clareira de mata de restinga na Reserva Biológica Estadual da Praia do Sul (RJ). Rev. Bras. Ecol. 1(2): 36-43.

Bacchi, O.; Leitão Filho, H. F. \& Aranha, C. 1984. Plantas invasoras de culturas no Estado de São Paulo. v.3. Campinas, Editora da Unicamp. 601906p

Boldrini, I. I. \& Miotto, S. T. S. 1987. Levantamento fitossociológico de um campo limpo da Estação Experimental Agronômica, UFRGS, Guaíba, RS. Acta bot. bras. 1(1): 49-56.

Boldrini, I. I. \& Eggers, L. 1996. Vegetação campestre do Sul do Brasil: dinâmica de espécies à exclusão do gado. Acta bot. bras. 10(1): 37-50.

Brinkmann, W. L. F. \& Vieira, A. N. 1971. The effect of burning on germination of seeds at different soil depths of various tropical tree species. Turrialba. 21(1): 77-82.

Buschbacher, R. Uhl, C \& Serrão, E. A. S. 1984. Forest development following 
pasture use in the north of Pará, Brazil. Resumos. $1^{\circ}$ Simpósio do Trópico Úmido. EMBRAPA, Belém. : 409-410.

Buselato, T. C. \& Bueno, O. L. 1981. Composição florística de dois campos localizados no município de Montenegro, Rio Grande do Sul, Brasil. Iheringia. Sér. Bot. 26: 65-84.

Castellani, T. T. 1986. Sucessão secundária inicial em mata decídua, após perturbação por fogo. Campinas, Universidade Estadual de Campinas, 180p. Dissertação de Mestrado. Instituto de Biologia.

Delamônica., P. 1997. Florística e estrutura de floresta atlântica secundária Reserva Biológica Estadual da Praia do Sul, Ilha Grande, RJ. São Paulo, Universidade de São Paulo, 113p. Dissertação de Mestrado. Instituto de Biociências.

Fabris, L. C. \& Pereira, O. J. 1990. Análise fitossociológica na formação pós-praia da restinga de Setiba - Guarapari - ES. Santo. II Simpósio de ecossistemas da costa sul e sudeste brasileira : estrutura, função e manejo. vol. 3 . Academia de Ciências do Estado de São Paulo :455-466.

Gavillanes, M. L \& D'Angieri Filho, C. N. 1991. Flórula ruderal da cidade de Lavras, MG. Acta bot. bras. 5(2): 7788.

Glenn-Lewin, D. C.; Peet, R. K.; Veben, T. T. 1992. Plant Succession. Theory and prediction. Population and community biology series 11. Chapman \& Hall. London. 352pp.

Guedes, R. R. 1988. Composição florística e estrutura de um trecho de mata perturbada de baixada no município de Magé, Rio de Janeiro. Arq. Jard. Bot. do Rio de Janeiro 29: 155-200.
Guillaumon, J. R.; Fontes, M de A. 1992. Estudo para manejo dos campos antrópicos do Parque Estadual da Ilha Anchieta - Zona de recuperação. Anais $2^{\circ}$ Congresso Nacional sobre Essências Nativas :867-879.

Holl, K. D. 1999. Tropical montane forest recovery in abandoned pasture in Costa Rica: obstacles and opportunities. Tropical Restoration for the new millennium . International Conference $4^{\text {th }}$ Annual . Abstracts: 72 . IBDF/FBCN. 1981. Plano de manejo Reserva Biológica de Poço das Antas. Brasília. Ministério da Agricultura. 95p.

Kissmann, K. G. \& Groth, D. 1997. Plantas infestantes e nocivas. Tomo I, II, III. São Paulo. BASF Brasileira S.A. 2a . ed. 603p.

Laca-Buendia, J. P., Brandão, M. \& Gavilanes, M. L. 1989. Plantas invasoras da cultura do feijoeiro (Phaseolus vulgaris L.) no Estado de Minas Gerais. Acta bot. bras. 3(2); 225-236.

Leitão Filho, H. F.; Aranha, C. \& Bacchi, O. 1972. Plantas invasoras de culturas no Estado de São Paulo. v.1. São Paulo, HUCITEC. 291p._ 1975. Plantas invasoras de culturas no Estado de São Paulo. v.2. São Paulo, HUCITEC. 297-597p.

Mack, M. C. \& D’Antonio, C. M. 1998. Impacts of biological invasions on disturbance regimes. Trends Ecol. Evol.. 13(5): 195-198.

Mantovani, W. 1987. Análise florística e fitossociológica do estrato herbáceosubarbustivo do cerrado na Reserva Biológica de Mogi-Guaçu e em Itirapina, $S P$. Campinas, Universidade Estadual de Campinas, 203p. Tese de Doutorado. Instituto de Biologia. 
1993. Estrutura e dinâmica da floresta atlântica na Juréia, Iguape-SP. São Paulo, Universidade de São Paulo, 126p. Tese de Livre Docência .Instituto de Biologia, Departamento de Ecologia Geral.

\& Martins, F. R. 1990. O método de pontos. Acta bot. bras. 4(2): 95-122.

Matthes, L. A. F. 1992. Dinâmica da sucessão secundária em mata, após a ocorrência de fogo - Santa Genebra Campinas, São Paulo. Campinas, Universidade Estadual de Campinas, 216p. Tese de Doutorado. Instituto de Biologia.

Montezuma, R. C. M. 1997. Estrutura da vegetação de uma restinga de Ericaceae no município de Carapebus - RJ. Rio de Janeiro, Universidade Federal do Rio de Janeiro, 102p. Dissertação de Mestrado. Instituto de Biologia.

Muenscher, W. C. 1955. Weeds. The Macmillan Company. New York. 2a. ed. $560 \mathrm{p}$.

Myster, R. W. 1993. Tree invasion and establishment in old field at Hutcheson Memorial Forest. The Bot. Rev. 59(4): 251-272.

Nepstad, D. C.; Uhl, C. \& Serrão, E. A. S. 1991. Recuperation of a degraded amazonian landscape: forest recovery and agricultural restoration. Ambio 20(6): 248-255.

Odum, E. P. 1972. Ecologia. México. Nueva Editorial Interamericana. 3a ed. 639 p.

Pessoa, S. de V. A.; Guedes-Bruni, R. R. \& Kurtz, B. C. 1997. Composição florística e estrutura do componente arbustivoarbóreo de um trecho secundário de floresta montana na Reserva Ecológica de Macaé de Cima. In. Lima, H.C. de
\& Guedes-Bruni, R.R. (eds.) Serra de Macaé de Cima: Diversidade Florística e Conservação em Mata Atlântica. Rio de Janeiro, Instituto de Pesquisas Jardim Botânico do Rio de Janeiro. p. 147-168.

Programa Mata Atlântica, 1996. Relatório Técnico Científico 1993-1996. Jardim Botânico do Rio de Janeiro/IBAMA.

Purata, S. E. 1986. Floristic and structural changes during old-field succession in the Mexican tropics in relation to site history and species availability. J. Trop. Ecol. 2: 257-276.

Sá, C. F. C. de. 1996. Regeneração em área de floresta de restinga na Reserva Ecológica Estadual de Jacarepiá, Saquarema, RJ: I- Estrato herbáceo. Arq. Jard. Bot. Rio Janeiro. 34(1): 177-192.

Tabarelli, M., Villani, J. P. \& Mantovani, W. 1993. Aspectos da sucessão secundária em trecho da floresta atlântica no Parque Estadual da Serra do Mar, SP. Revta. do Inst. Florestal. 5:101-114. 1994. Estudo comparativo de dois trechos de floresta atlântica secundária, no Núcleo Santa Virgínia do Parque Estadual da Serra do Mar. Revta. do Inst. Florestal 6: 1-6.

Takizawa, F. H. 1995. Levantamento pedológico e zoneamento ambiental da Reserva Biológica de Poço das Antas. Piracicaba, Escola Superior de Agricultura Luis de Queiroz/USP. 56p. Monografia de Graduação. Depart. Ciências do Solo.

Uhl, C.; Clark, H.; Clark, K. \& Maquirino, P. 1982. Successional patterns associated with slash-and-burn agriculture in the upper Rio Negro region of the Amazon basin. Biotropica. 14: 249-254. 
, Buschbacher, R. \& Serrão, E.

A. S.1988. Abandoned pastures in eastern Amazonia. I. Patterns of plant sucession. J. Ecol. 76: 663-681.

Velloso, H. P., Rangel Filho, A. L. R. \& Lima, J. C. A.1991. Classificação da vegetação brasileira adaptada a um sistema universal . Rio de Janeiro, IBGE. 124p.

Vieira, I. C. G.; Uhl. C. \& Nepstad, D.1994. The role of the shrub Cordia multispicata as a "sucession facilitator" in an abandoned pasture in Paragominas, Amazonia. Vegetatio 115: 91-99.

Zaluar, H. L. T. 1997. Espécies focais e a formação de moitas na restinga aberta de Clusia, Carapebus, RJ. Rio de Janeiro, Universidade Federal do Rio de Janeiro. 93p. Dissertação de Mestrado. Instituto de Biologia.

Zahawi, R. A \& Augspurger, C. K. 1999. Early plant sucession in abandoned pastures in Ecuador. Biotropica 31(4):540-552.

Zocche, J. J. \& Porto, M. L. 1993. Florística e fitossociologia de campo natural sobre banco de carvão em áreas mineradas, Rio Grande do Sul, Brasil. Acta bot. bras. 6(2): 47-84. 